\title{
The Stabilizing Role of Government Size*
}

\author{
Javier Andrés ${ }^{a}$, Rafael Doménech ${ }^{a}$ and Antonio Fatás ${ }^{b}$ \\ a University of Valencia \\ $b$ INSEAD
}

March, 2004.

\begin{abstract}
This paper presents an analysis of how alternative models of the business cycle can replicate the stylized fact that large governments are associated with less volatile economies. Our analysis shows that adding nominal rigidities and costs of capital adjustment to an otherwise standard RBC model can generate a negative correlation between government size and the volatility of output. However, in the model, we find that the stabilizing effect is only due to a composition effect and it is not present when we look at the volatility of private output. Given that empirically we also observe a negative correlation between government size and the volatility of consumption, we modify the model by introducing rule-of-thumb consumers. In this modified version of our initial model we observe that consumption volatility is also reduced when government size increases.
\end{abstract}

Keywords: Government size, output volatility, automatic stabilizers.

JEL Classification: E32, E52, E63.

\section{Introduction}

This paper provides a study of how alternative models of the business cycle can replicate the stylized fact that across countries and even U.S. states large governments are associated with less volatile economies. There is substantial evidence that countries or regions with large governments display less volatile economies, as shown in Galí (1994) and Fatás and Mihov (2001). This is not only an intriguing fact for macroeconomists, but also one that has implications regarding the models we use to analyze economic fluctuations. As it is the case that most macroeconomic theories incorporate governments

* Financial support by CICYT grant SEC2002-0026 and EFRD is gratefully acknowledged. e-mails for comments: javier.andres@uv.es, rafael.domenech@uv.es and fatas@econ.insead.edu. 
in one form or another (expenditures, transfers or taxes), understanding this correlation is crucial to improve the ability of models to replicate the stylized facts of the business cycle.

The approach of this paper is to explore alternative theories and probe into the different mechanisms that may explain why government size can have an effect on the volatility of output fluctuations. Although we replicate and present some of the evidence provided by previous papers in the literature, our goal is not to challenge or qualify this empirical fact. We take as given that the size of governments is inversely correlated with the volatility of business cycles and we look for an explanation. Finding this explanation is a challenging task given that, as shown by Galí (1994), there is no clear connection between government size and volatility in the context of a standard RBC model. In fact, under some reasonable assumptions, that model produces a positive correlation.

Our paper, by clearly illustrating the mechanisms behind the effects of taxes and government spending on macroeconomic outcomes under different theoretical assumptions, can be useful in discriminating among different business cycle models. We compare the predictions of a standard RBC model to those of models that incorporate nominal rigidities, costs of adjustment for capital and rule-of-thumb consumers. There are several reasons why we consider a framework in which several frictions are present. First, these are models that are more likely to generate the type of Keynesian effects observed in the data. For example, adding costs of adjustment to capital is a way of making investment less reactive to technology shocks and, as a result, replicate better the behavior in the data. A second reason for looking into this class of models is that they are increasingly being used by researchers who struggle to explain other puzzles also related to fiscal policy. For example, there is evidence that consumption increases in response to exogenous increases in government spending (see Fatás and Mihov, 2002, or Perotti, 2002). This fact, which is again at odds with the standard RBC model, has been partially accounted for in a recent paper by Galí, López-Salido and Vallés (2003) using a model with similar features to the ones we explore in our paper.

Focusing on a very precise correlation (that between government size and output volatility) is a way of comparing the relative merits of models of the business cycle that complements the more traditional matching of moments of the data. For example, as shown in Christiano and Eichenbaum (1992), some of the initial puzzles of RBC models can be resolved by the inclusion of additional sources of shocks. However, Galí (1999) argues that even if the model can replicate the unconditional moments of the data, it may provide a distorted picture of the economy's response to each of the shocks.

From an empirical point of view, understanding the implications of the correlation between government size and output volatility is important for the design of stabilizing 
fiscal policies. The fact that larger governments are associated with lower volatilities can lead to the easy temptation of arguing that this is the result of automatic stabilizers but to be able to make that assertion one first needs to understand the stabilizing properties of large governments in a dynamic stochastic general equilibrium model.

Our main findings are the following. First, our analysis shows that adding nominal rigidities and costs of capital adjustment to an otherwise standard RBC model can generate a negative correlation between government size and the volatility of output. However, in the model, we find that the stabilizing effect is only present because of a composition effect, given that larger goverments are not associated, in the calibrated model, with more stable private consumption or investment. In fact, as government size increases, these two components of aggregate expenditure become more volatile. There is still an interesting interaction between the degree of rigidities and the volatility of these two components of GDP. As we increase the degree of rigidities in the model, the increase in the volatility of consumption and investment as government size increases is smaller. This interaction is, nonetheless, of second order importance since we observe a negative correlation between government size and the volatility of both components.

Given that empirically we observe that consumption volatility is also negatively correlated with government size, we explore and additional variation of the initial model in which we introduce rule-of-thumb consumers in an attempt to have consumption closely mimic the response of GDP. In this modified version of our initial model we indeed observe that consumption volatility is also reduced when government size increases.

The structure of this paper is as follows. In section 2 we present the basic empirical evidence about the negative correlation between government size and output and consumption volatility. In the third section we describe our model with nominal and real rigidities. Its main implications in terms of the relationship between government size and macroeconomic volatility are explored in Section 4, where we also extend our basic model to the inclusion of rule-of-thumb consumers to better account for the empirical evidence. Finally, section 5 concludes.

\section{Empirical evidence}

We first present evidence of the negative correlation between government size and business cycle volatility. This correlation has been documented by, among others, Galí (1994) and Fatás and Mihov (2001). We measure government size by the log of the GDP share of total government expenditures $(\ln G / Y)$. When it comes to output volatility, we follow an eclectic approach and use four different measures that use different detrending methods. Table 1 presents the main results. Column (1) reproduces Fatás and Mihov's (2001) 
results for the period 1960-97, using the standard deviation of GDP $(\Delta \ln Y)$ growth rates as a measure of output volatility. Size of governments is negatively correlated with the volatility of output growth. Column (2) produces a similar result but now we are using the standard deviation of the GDP per capita growth rates $(\Delta \ln y)$ as dependent variable.

The reduced-form approach of columns (1) and (2) have a difficult interpretation because of the possibility of mispecifications in the regression. For example, it could be that differences in volatility across OECD countries are not driven by business cycle phenomenon but by transitional growth dynamics that become part of the measured volatility because we are looking at deviations around a flat trend (when using growth rates). To correct for this possibility, we include in our regressions income per capita in 1960 as a control. We expect those countries with lower per capita income in 1960 to grow at a higher rate than other economies which were closer to theirs steady states. This hypothesis is corroborated in column (3) where the coefficient of $\ln (G / Y)$ almost halves with respect to that in column (2) whereas the log of the GDP per capita in 1960 is negative and very significant, with a sizable improvement in the fit of the regression.

An alternative way of dealing with the influence of transitional dynamics in our measure of volatility is to use the cyclical component of the GDP (in logs), obtained with the HP filter and a smoothing parameter equal to 10 since we are using annual data (see Baxter and King (1999), and Maravall and del Rio (2001)). In column (4) the dependent variable is the standard deviation of the output gap $\left(Y^{c}\right)$, whereas in columns (5) and (6) it is the standard deviation of the cyclical component of GDP per capita $\left(y^{c}\right)$. We need to stress that in all cases, the coefficient of $\ln (G / Y)$ is negative and very significant, although lower in absolute terms than the values estimated in columns (1) and (2), confirming that transitional dynamics have played an important role. An additional robustness test is presented in column (7) where we include a dummy for Portugal and Finland, which show a very large output volatility of the cyclical component of the GDP.

We have analyzed the inclusion of some additional regressors as Fatás and Mihov (2001): openness, the average log of GDP per capita, the log of GDP (to control for the economy size) and the average rate of growth of GDP per capita $(\overline{\Delta \ln y})$. Neither of them is statistically significant and their inclusion does not affect the significance of the government size coefficient.

There is also the possibility of reverse causation in this regression. The reverse causation can bias our results in many directions. For example, it could be that economies that are very volatile (for example because they are very open) will have larger governments that serve as an insurance against cyclical shocks (see Rodrik, 1998). If this were the case, the coefficient in the regressions above would be biased towards zero. The 
Table 1

Government size and output volatility

\begin{tabular}{lrrrrrrrr}
\hline \hline & \multicolumn{7}{c}{ Dependent variable: standard deviation of } \\
\cline { 2 - 9 } & $\Delta \ln Y$ & $\Delta \ln y$ & $\Delta \ln y$ & $Y^{c}$ & $y^{c}$ & \multicolumn{1}{c}{$y^{c}$} & \multicolumn{1}{c}{$\Delta \ln c$} & \multicolumn{1}{c}{$\Delta \ln c$} \\
& $(1)$ & $(2)$ & \multicolumn{1}{c}{$(3)$} & \multicolumn{1}{c}{$(4)$} & \multicolumn{1}{c}{$(5)$} & \multicolumn{1}{c}{$(6)$} & \multicolumn{1}{c}{$(7)$} & \multicolumn{1}{c}{$(8)$} \\
\hline $\ln (G / Y)$ & -0.0190 & -0.0200 & -0.0115 & -0.0092 & -0.0110 & -0.0080 & -0.0200 & -0.0116 \\
& $(4.19)$ & $(3.87)$ & $(2.60)$ & $(3.17)$ & $(2.94)$ & $(3.84)$ & $(2.52)$ & $(2.25)$ \\
$d$ & & & & & & 0.0082 & -0.0140 & -0.0100 \\
& & & & & & $(11.4)$ & $(3.36)$ & $(4.45)$ \\
$\ln \left(\frac{X+M}{Y}\right)$ & & & & & & & & \\
& & & & & & & & \\
$\ln y$ & & & -0.0084 & & & & & -0.0058 \\
& & & $(4.02)$ & & & & & $(1.60)$ \\
$\bar{R}^{2}$ & 0.3857 & 0.3537 & 0.5875 & 0.1986 & 0.2479 & 0.7029 & 0.3903 & 0.4148 \\
$\frac{\partial \ln \sigma_{i}}{\partial \ln (G / Y)}$ & -0.7194 & -0.7625 & -0.4463 & -0.6341 & -0.7208 & -0.5579 & -0.7170 & -0.4495 \\
& $(4.12)$ & $(3.83)$ & $(2.40)$ & $(3.30)$ & $(3.26)$ & $(3.70)$ & $(2.87)$ & $(2.22)$ \\
\hline \hline
\end{tabular}

possibility of endogeneity in this specification is dealt with in detail in Fatás and Mihov (2001), who show that after controlling for endogeneity, the negative correlation is still present and, in some cases, becomes more significant (from both an economic and statistical point of view).

Finally in columns (7) and (8) we present the correlation between the volatility of private consumption growth $(\Delta \ln c)$ and government size. As it is clear from both columns, there is also a negative and significant correlation between both variables, suggesting that the results of columns (1) to (6) cannot be explained solely by the composition effect of aggregate demand as the share of public consumption becomes larger. The magnitude of the elasticity of the standard deviation of consumption to government size is similar to the one we obtain in the case of output.

From the point of view of this paper, we take as given the empirical finding that there is a negative correlation between government size and business cycles. This simple correlation between size of government and volatility has been refined by several recent studies. There have been attempts to clarify the origin of this correlation. For example, Martinez-Mongay (2002) and Martinez-Mongay and Sekkat (2003) have looked at which measure of government size captures this correlation better (e.g., personal versus indirect taxes). Others have looked at the possibility that the correlation of Table 1 is not linear and can be reversed for large government size (Silgoner, Reitschuler, Crespo-Cuaresma (2003)). We will ignore these refinements and simply postulate a model that can account for the negative correlation observed in Table 1. 


\section{The model}

As mentioned in the introduction, the fact that government size is negatively correlated with the size of the business cycle is difficult to reconcile with a standard RBC model (Galí (1994)). The failure of the RBC framework to replicate some basic features of the business cycle with respect to fiscal policy is not unique to this stylized fact. For example, in the recent literature that looks at the dynamic effects of fiscal policy changes (Blanchard and Perotti (2002) Fatás and Mihov (2002), Perotti (2002)) there is evidence that consumption tends to respond positively to increases in government spending, a result that does not square well with the predictions of the RBC model.

Both of these facts are easily explained by a simple textbook IS-LM model. This simple static model predicts both that government size is negatively correlated with the volatility of output and that consumption increases when government spending increases. In that sense, these results have a Keynesian flavor that speaks in favor of the stabilizing role of government spending. This effect is also present in large scale macroeconometric models where automatic stabilizers are linked to government size (see van den Noord (2000) and Buti and van den Noord (2003)). Thus, our search for an explanation starts with a basic dynamic general equilibrium model to which we add some Keynesian features: nominal inertia and adjustments to investment costs. Our model is very similar to the one proposed by Andrés and Doménech (2003) and also displays many features of the analysis of Galí, López-Salido and Vallés (2003), who attempt to provide a theoretical explanation for the observed positive response of consumption to government spending changes.

We now describe the main building blocks of the model, emphasizing the assumptions that should help us account for the empirical results of Table 1.

\subsection{Firms and households}

Price setting: nominal inertia

The economy is populated by $i$ intermediate goods producing firms. Each firm faces a downward sloping demand curve for its product $\left(y_{i}\right)$ with finite elasticity $\varepsilon$

$$
y_{i t}=y_{t}\left(\frac{P_{i t}}{P_{t}}\right)^{-\varepsilon}
$$

where $\left[\int_{0}^{1}\left(y_{i t}\right)^{\frac{\varepsilon-1}{\varepsilon}} d i\right]^{\frac{\varepsilon}{\varepsilon-1}}=y_{t}$ and $P_{t}=\left[\int_{0}^{1}\left(P_{i t}\right)^{1-\varepsilon} d i\right]^{\frac{1}{1-\varepsilon}}$. Following Calvo (1983), each period a measure $1-\phi$ of firms set their prices, $\widetilde{P}_{i t}$, to maximize the present value 
of future profits,

$$
\max _{\widetilde{P}_{i t}} E_{t} \sum_{j=0}^{\infty} \rho_{i t, t+j}(\beta \phi)^{j}\left[\widetilde{P}_{i t} \bar{\pi}^{j} y_{i t+j}-P_{t+j} m c_{i t, t+j}\left(y_{i t+j}+\kappa\right)\right]
$$

subject to

$$
y_{i t+j}=\left(\widetilde{P}_{i t} \bar{\pi}\right)^{-\varepsilon} P_{t+j}^{\varepsilon} y_{t+j}
$$

where $\rho_{t, t+j}$ is a price kernel representing the marginal utility value to the representative household of an additional unit of profits accrued in period $t+j, \beta$ the discount factor, $m c_{t, t+j}$ the marginal cost at $t+j$ of the firm changing prices at $t$ and $\kappa$ a fixed cost of production. The remaining ( $\phi$ per cent) firms set $P_{i t}=\bar{\pi} P_{i t-1}$ where $\bar{\pi}$ is the steadystate rate of inflation. We shall further assume that capital cannot be instantaneously reallocated across firms, so that the marginal cost of firms adjusting prices differ from those not adjusting at time $t$ (see Sbordone (2002)).

Capital and labor demand: cost minimization.

The optimal combination of capital $(k)$ and labor $(l)$ is obtained from the cost minimization process of the firm:

$$
\min _{k_{i t}, l_{i t}}\left(r_{t} k_{i t}+w_{t} l_{i t}\right)
$$

subject to

$$
y_{i t}=A_{t} k_{i t}^{\alpha} l_{i t}^{1-\alpha}-\kappa
$$

where $w_{t}$ is the real wage and $r_{t}$ is the rental cost of capital. The variable $A_{t}$ stands for the total factor productivity.

Aggregating the first order conditions of this problem we obtain the demand for labor $\left(l_{t}\right)$ and capital $\left(k_{t}\right)$,

$$
\begin{gathered}
w_{t}=m c_{t}(1-\alpha) A k_{t}^{\alpha} l_{t}^{-\alpha} \\
r_{t}=m c_{t} \alpha A k_{t}^{\alpha-1} l_{t}^{1-\alpha}
\end{gathered}
$$

\section{Households}

The utility function of the representative $j_{t h}$ household is non separable in leisure $\left(1-l_{t}\right)$ and consumption $\left(c_{t}\right)$ and separable in public consumption $\left(g_{t}^{c}\right)$ and investment, as in 
Baxter and King (1993):

$$
U\left(c_{t}, 1-l_{t}, g_{t}^{c}, g_{t}^{p}\right)=\frac{\left(c_{t}\left(1-l_{t}\right)^{\gamma}\right)^{1-\sigma}-1}{1-\sigma}+\Gamma\left(g_{t}^{c}, g_{t}^{p}\right)
$$

There is a cash-in-advance constraint that links the money demand $\left(M_{t}\right)$ and current cash transfers $\left(\tau_{t}^{m}\right)$ to consumption,

$$
P_{t}\left(1+\tau_{t}^{c}\right) c_{t} \leq M_{t}+\tau_{t}^{m}
$$

Households allocate their income (labor income, capital income, interest payments on bond holdings $\left(B_{t}\right)$, their share of profits of the firms $\left(\Omega_{i t}\right)$, and public transfers $\left.\left(P_{t} g_{t}^{s}\right)\right)$ and current cash holdings to buy consumption and investment goods $\left(e_{t}\right)$, and to accumulate savings either in bonds or money holdings for $t+1$ :

$$
\begin{aligned}
& M_{t+1}+\frac{B_{t+1}}{\left(1+i_{t+1}\right)}+P_{t}\left(1+\tau_{t}^{c}\right) c_{t}+P_{t} e_{t} \\
& =P_{t}\left(1-\tau_{t}^{w}\right) w_{t} l_{t}+P_{t}\left(1-\tau_{t}^{k}\right) r_{t} k_{t}+B_{t}+M_{t}+\tau_{t}^{m}+P_{t} g_{t}^{s}+\int_{0}^{1} \Omega_{i t} d i
\end{aligned}
$$

The tax structure includes taxes on labor income $\left(\tau_{t}^{w}\right)$, capital income $\left(\tau_{t}^{k}\right)$ and consumption $\left(\tau_{t}^{c}\right)$. The accumulation of capital results from the households' investment decisions. Due to installation costs $\Phi\left(e_{t} / k_{t}\right)$ only a proportion of investment spending goes to increase the capital stock

$$
k_{t+1}=\Phi\left(\frac{e_{t}}{k_{t}}\right) k_{t}+(1-\delta) k_{t}
$$

where $\delta$ is the constant depreciation rate.

\subsection{Equilibrium}

The symmetric monopolistic competition equilibrium is defined as the set of quantities that maximizes the constrained present value of the stream of utility of the representative household and the constrained present value of the profits earned by the representative firm, and the set of prices that clears the goods markets, the labor market and the money, bonds and capital markets. The extensive representation of the aggregate symmetric 
equilibrium is: ${ }^{2}$

$$
\begin{aligned}
& k_{t+1}=\Phi\left(\frac{e_{t}}{k_{t}}\right) k_{t}+(1-\delta) k_{t} \\
& \frac{\left(1-\tau_{t}^{w}\right)}{\left(1+\tau_{t}^{c}\right)} w_{t}=\frac{\gamma c_{t}}{\left(1-l_{t}\right)} \\
& \lambda_{t} \beta^{-1}=E_{t}\left(\lambda_{t+1} \frac{1+i_{t+1}}{\pi_{t+1}}\right) \\
& q_{t}=\left[\Phi^{\prime}\left(\frac{e_{t}}{k_{t}}\right)\right]^{-1} \\
& \frac{q_{t}}{\beta}=E_{t}\left\{\frac{\lambda_{t+1}}{\lambda_{t}}\left(\left(1-\tau_{t+1}^{k}\right) r_{t+1}+q_{t+1}\left[\Phi\left(\frac{e_{t+1}}{k_{t+1}}\right)+(1-\delta)-\Phi^{\prime}\left(\frac{e_{t+1}}{k_{t+1}}\right) \frac{e_{t+1}}{k_{t+1}}\right]\right)\right\} \\
& \frac{M_{t}}{P_{t}}+\frac{\tau^{m}}{P_{t}}=\left(1+\tau_{t}^{c}\right) c_{t} \\
& w_{t}=m c_{t}(1-\alpha) A k_{t}^{\alpha} l_{t}^{-\alpha} \\
& r_{t}=m c_{t} \alpha A k_{t}^{\alpha-1} l_{t}^{1-\alpha} \\
& \widetilde{P}_{t}=\frac{\varepsilon}{\varepsilon-1} \frac{\sum_{j=0}^{\infty}(\beta \phi)^{j} E_{t}\left[\rho_{t, t+j} P_{t+j}^{\varepsilon+1} m c_{t+j} y_{t+j} \bar{\pi}^{-j \varepsilon}\right]}{\sum_{j=0}^{\infty}(\beta \phi)^{j} E_{t}\left[\rho_{t, t+j} P_{t+j}^{\varepsilon} y_{t+j} \bar{\pi}^{j(1-\varepsilon)}\right]} \\
& P_{t}=\left[\phi\left(\bar{\pi} P_{t-1}\right)^{1-\varepsilon}+(1-\phi) \widetilde{P}_{t}^{1-\varepsilon}\right]^{\frac{1}{1-\varepsilon}}
\end{aligned}
$$

2 The model solution, the equilibrium, the steady state and the dynamic system can be downloaded from http://iei.uv.es/ rdomenec/ADFatas/tech_appendix.pdf 


$$
\begin{gathered}
\pi_{t} \equiv \frac{P_{t}}{P_{t-1}} \\
P_{t} \tau_{t}^{w} w_{t} l_{t}+P_{t} \tau_{t}^{k} r_{t} k_{t}+P_{t} \tau_{t}^{c} c_{t}-P_{t}\left(g_{t}^{c}+g_{t}^{p}+g_{t}^{s}\right)=-\frac{B_{t+1}}{\left(1+i_{t+1}\right)}+B_{t}-M_{t+1}+M_{t} \\
y_{t}=c_{t}+e_{t}+g_{t}^{c}+g_{t}^{p} \\
y_{t}=A k_{t}^{\alpha} l_{t}^{1-\alpha}\left(g_{t}^{p}\right)^{\theta}-\kappa \\
\frac{E_{t} \rho_{t, t+j}}{E_{t} \rho_{t, t+j-1}}=\frac{E_{t}\left(\lambda_{t+j} / P_{t+j}\right)}{E_{t}\left(\lambda_{t+j-1} / P_{t+j-1}\right)}
\end{gathered}
$$

where $\lambda_{t}$ is the Lagrange multiplier of the intertemporal decision problem of the household.

The model is completed with the rules of the policy instruments: $i_{t}, g_{t}^{c}, g_{t}^{p}, g_{t}^{s}$. The monetary rule can be specified in either $i_{t}$ or $M_{t}$, and the fiscal rules determine the path of $\left(g_{t}^{c}, g_{t}^{p}, g_{t}^{s}\right)$. All $\tau_{t}^{w}, \tau_{t}^{k}$ and $\tau_{t}^{c}$ will be assumed constant for all $t$ unless said otherwise. Monetary policy is represented by a standard Taylor rule:

$$
i_{t}=\rho_{r} i_{t-1}+\left(1-\rho_{r}\right) \bar{i}+\left(1-\rho_{r}\right) \rho_{\pi}\left(\pi_{t}-\bar{\pi}\right)+\left(1-\rho_{r}\right) \rho_{y} \widehat{y}_{t}+z_{t}^{i}
$$

in which the monetary authority sets the interest rate $\left(i_{t}\right)$ to prevent inflation deviating from its steady-state level $\left(\pi_{t}-\bar{\pi}\right)$ and to counteract movements in the output gap $\left(\widehat{y}_{t}\right)$; $\bar{i}$ is the steady-state interest rate and the current rate moves smoothly $\left(0<\rho_{r}<1\right)$ and has an unexpected component, $z_{t}^{i}$.

Provided that $\rho_{\pi}$ is above certain threshold value, fiscal policy must be designed to satisfy the present value budget constraint of the public sector for any price level in order to obtain a unique monetary equilibrium (Leeper (1993), Woodford (1995), Leith and Wren-Lewis (2001)). A simple way of making this requirement operational is to assume that either taxes or public spending respond sufficiently to the level of debt (Canzoneri, Cumby and Diba (2001)). These feedback rules also represent the quantitative deficit and/or debt targets made explicit in most developed countries' fiscal systems nowadays (Corsetti and Roubini (1996), Bohn (1998) and Ballabriga and Martinez-Mongay (2002)). 
Table 2

Calibration of baseline model

\begin{tabular}{cccccccc}
\hline \hline$\sigma$ & $\beta$ & $\gamma$ & $\alpha$ & $\varepsilon$ & $\delta$ & $\sigma_{z}$ & $\rho_{z}$ \\
1.0 & $1.03^{-\frac{1}{4}}$ & 1.295 & 0.40 & 6.0 & 0.021 & 0.0078 & 0.80 \\
\hline$\tau^{w}$ & $\tau^{k}$ & $\tau^{c}$ & $g^{c} / y$ & $g^{s} / y$ & $\rho_{r}$ & $\rho_{\pi}$ & $\pi$ \\
0.279 & 0.279 & 0.10 & 0.18 & 0.16 & 0.5 & 1.5 & $1.02^{0.25}$ \\
\hline \hline
\end{tabular}

The theoretical requirements of a Ricardian policy can be satisfied with a feedback behaviour of either revenues or expenditures, but the empirical evidence indicates that successful consolidations in industrialized countries have been based on spending cuts (see von Hagen, Hallet and Strauch (2001), Alesina and Perotti (1997)). ${ }^{3}$ For simplicity, we use a fiscal rule in lump-sum transfers as a function of the absolute deviations of public debt from its steady-state value $\bar{b}=0$.

\subsection{Calibration}

We obtain a numerical solution of the steady state as well as of the log-linearized system. Table 2 summarizes the values of the calibrated baseline parameters. The relative risk aversion coefficient $(\sigma)$ is 2.0 , the discount factor $(\beta)$ is 0.9926 , following Christiano and Eichenbaum (1992), and, since we assume that in the steady state households allocate $1 / 3$ of their time to market activities (as in Cooley and Prescott (1995)), the share of consumption in utility $(\gamma)$ has been chosen to be 1.295 .

The elasticity of output with respect to private capital $(\alpha)$ is 0.40 , as in Cooley and Prescott (1995). The depreciation rate $(\delta)$ is equal to 0.021 as estimated by Christiano and Eichenbaum (1992). The standard deviation $\left(\sigma_{z}\right)$ and the first order autocorrelation coefficient $\left(\rho_{z}\right)$ of the technology shock are set to 0.0078 and 0.80 respectively. These values have been chosen in order to produce GDP cycles that mimic the volatility of output observed in European countries in our baseline model (see Agresti and Mojon (2001)). ${ }^{4}$ Following Christiano, Eichembaum and Evans (1997), the elasticity of demand with respect to price $(\varepsilon)$ is set to 6.0 , consistent with a steady-state mark-up, $\varepsilon /(\varepsilon-1)$, equal to 1.20 . The fixed cost in production $(\kappa)$ is then solved as a function of $y$ and $\varepsilon$ to

3 Cyclical changes in tax rates are not very realistic and may, under some circumstances, lead to multiple (sunspot) equilibria, thus inducing additional instability (Schmitt-Grohé and Uribe (1988))

4 In any case, it is important to notice that the elasticity of output and consumption volatilities to government size are invariant to the choice of $\sigma_{z}$. 
produce zero profits in the steady-state:

$$
\kappa=\frac{\bar{y}}{\varepsilon-1}
$$

Fiscal policy parameters have been calibrated after computing the tax rates for OECD countries using the method proposed by Mendoza, Razin and Tesar (1994). Given these numbers, we assume for simplicity that there is a unique income tax $\left(\tau^{k}=\tau^{w}=\right.$ $0.279)$ whereas consumption taxes $\left(\tau^{c}\right)$ are equal to 0.10 . For the same sample of countries and years, government consumption over GDP $\left(\bar{g}^{c} / \bar{y}\right)$ is 0.18 and transfers $\left(\bar{g}^{s} / \bar{y}\right)$ are 0.16 . This calibration yields no public debt in steady state, whereas the response of transfers to absolute deviations of debt from its steady state is set at 0.15 .

The last set of parameters refers to the interest rate rule. In the baseline model, we set the autocorrelation coefficient of the interest rate $\left(\rho_{r}\right)$ equal to 0.5 and the response to inflation deviations from target $\left(\rho_{\pi}\right)$ equal to 1.5 . These values imply a response of the interest rate to inflation slightly quicker and less aggressive than the one usually estimated for EMU countries (see, Doménech, Ledo and Taguas (2002)). The steadystate level of gross inflation $(\bar{\pi})$ is set to $1.02^{0.25}$, that is, the target level of the ECB. The model with supply shocks has been simulated 100 times, producing 200 observations. We take the last 100 observations and compute the steady-sate value $(\bar{x})$ and the standard deviation of each endogenous variable $\left(\sigma_{x}\right)$.

\section{Government size and output volatility.}

We have simulated the model under different configurations of parameters to assess how the size of the government affects the volatility of output. Government size will be captured by a parameter $\eta$ that will scale both expenditures and revenues so that the steady state budget remains balanced. In other words, we will start with a baseline economy $(b)$ and we will then look at transformations $(j)$ in which government expenditures and tax rates are proportional to those of the benchmark model:

$$
\begin{gathered}
\tau_{j}^{i}=\eta \tau_{b}^{i} \\
g_{j}^{i} / y_{j}=\eta g_{b}^{i} / y_{b}
\end{gathered}
$$

where $0.5 \leq \eta \leq 1.5$.

The first three columns of Table 3 present the standard deviation of output as well as its elasticity as we change government size $\left(\partial \ln \sigma_{y} / \partial \ln (G / Y)\right)$ for different configurations of parameters. We present this elasticity to be able to do a quick comparison with 
Table 3

Government size and output volatility

\begin{tabular}{lrrrrrrrr}
\hline \hline & \multicolumn{3}{c}{ Output } & & \multicolumn{3}{c}{ Consumption } \\
\cline { 2 - 3 } \cline { 6 - 8 } & $\sigma_{y}$ & $\sigma_{y}$ & $\frac{\partial \ln \sigma_{y}}{\partial \ln (G / Y)}$ & & $\sigma_{c}$ & $\sigma_{c}$ & $\frac{\partial \ln \sigma_{c}}{\partial \ln (G / Y)}$ \\
& $\eta=0.5$ & $\eta=1.5$ & & & $\eta=0.5$ & $\eta=1.5$ & \\
$\Theta=\phi=0$ & 2.179 & 2.134 & -0.020 & & 0.949 & 1.412 & 0.362 \\
$\Theta=0, \phi=0.75$ & 2.721 & 2.358 & -0.130 & & 1.107 & 1.480 & 0.265 \\
$\Theta=0.25, \phi=0$ & 1.630 & 1.437 & -0.115 & & 1.182 & 1.454 & 0.189 \\
$\Theta=0.25, \phi=0.75$ & 0.781 & 0.593 & -0.251 & & 0.642 & 0.664 & 0.030 \\
& & & & & & \\
\hline \hline
\end{tabular}

the results of Table 1 where the coefficients of the first row can be read as elasticities.

The four economies of Table 3 differ in their degree of price rigidities and in the size of the adjustment costs to capital. In the case where $\Theta=\phi=0.0$ we have a standard RBC model with no price rigidities or adjustment costs to investment. In this case we obtain results which are similar to the findings of Galí (1994). As government size increases, output volatility barely changes.

We now introduce nominal rigidities and costs of adjustment to investment to add Keynesian features to the economy. As expected, adding rigidities to the model makes the economy less volatile. This effect is mainly driven by the adjustment costs to capital, as can be seen by comparing rows 1 and 3 in Table 3. A comparison of rows 1 and 2 shows that the rigidity of prices can make the economy more volatile by itself. We are not interested in the overall volatility of output but on how this volatility changes as we change government size. We can see this effect by either comparing columns 1 and 2 , which are calculated by two different sizes of government, or by looking at the next column that contains the elasticity of output volatility with respect to government size.

What can be seen as we move down through rows 2 to 4 , is that, with rigidities, the volatility of output decreases more and more as we increase government size. In other words, adding rigidities to the RBC economy allows us to generate important stabilizing effects from government size. And these stabilizing effects are directly linked to the degree of rigidities present in the economy: as these rigidities increase this correlation becomes even more negative (i.e., larger in absolute size). For example, in the case where $\Theta=0.25$ and $\phi=0.75$ the elasticity of output volatility to government size is -0.25 , approximately half of the estimated elasticity in Table 1.

In Figure 1 we generalize the results of Table 1 by displaying this elasticity as a function of the values for two key parameters: the degree of nominal rigidities $(\phi)$ and 
capital adjustment costs $(\Theta)$. We observe a monotonic negative relationship between this elasticity and the degree of rigidities in the model. As rigidities increase, this elasticity decreases.

\subsection{Why do larger governments have less volatile business cycles?}

We now turn to the intuition of the results. What is the reason for the stabilizing effect of larger governments in our simulated economy? To understand this issue, we have looked at how the volatilities of different components of GDP change when government size changes. The last three columns of Table 3 present the volatility of consumption as well as the elasticity of this volatility relative to government size. Figure 2 generalizes the analysis to a wide range of parameter values for $\phi$ and $\Theta$.

The results for consumption are similar to those for output. For all parameters values we find that as we add rigidities to the model, the elasticity decreases. But the difference with our previous results is that the elasticity of consumption volatility never turns negative. In other words, it is always the case, for all parameter values considered, that government size has a destabilizing effect on consumption (i.e., the volatility of consumption always increases as governments become larger), although this effect becomes smaller as we increase the degree of rigidities. Although not reported in the table, the same effect is present when we look at investment. Therefore, for all parameter values considered so far, larger governments reduce the volatility of output only because of a composition effect. It is because government spending is not volatile itself and that we are increasing the size of the (non-volatile) component of GDP that the overall volatility decreases.

Why does consumption and investment volatility increase when $G / Y$ increases? This is a result that is already present in Galí (1994). Higher volatility comes as a result of an increase in the investment multiplier because a higher $G / Y$ implies a lower steadystate level of the capital-to-output ratio. A low level of capital relative to output implies a larger response of investment to changes in productivity. This is also the effect that justifies the larger increase in consumption, because of the more pronounced response of investment, the associated increase in wealth leads to a larger response of consumption.

There is a second possible effect that can explain this increase in volatility in private output: an increase in the labor elasticity. Higher $G / Y$ implies a lower steady-state level of employment, which will make the response of hours larger. This effect gets partially compensated in our model by a wealth effect that goes in the opposite direction: lower wealth leads to a lower elasticity of labor supply.

It is important to stress that, as we indicated above, despite the fact that our model predicts destabilizing effects of government size on consumption and investment 


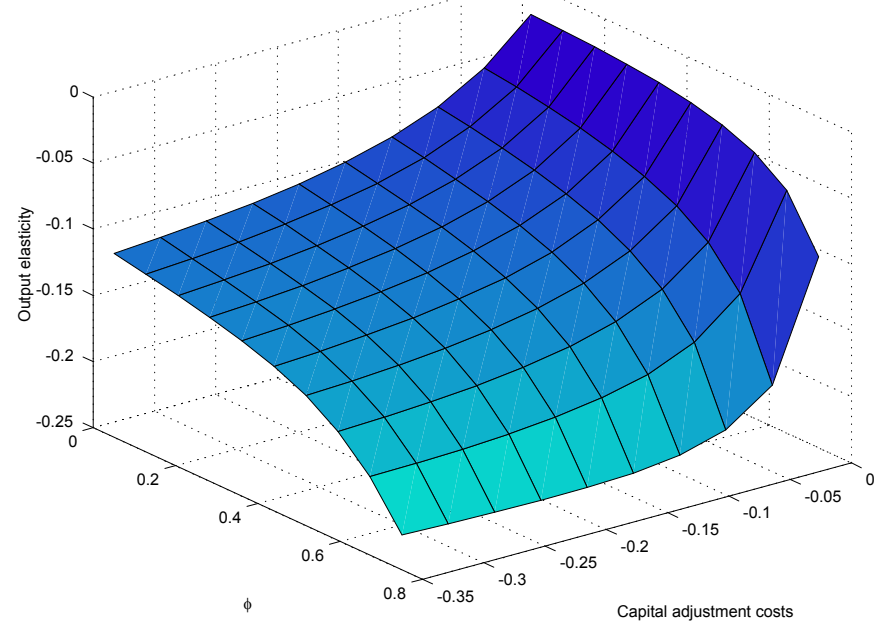

Figure 1: The elasticity of output volatility to government size as a function of nominal and real rigidities when public consumption is acyclical.

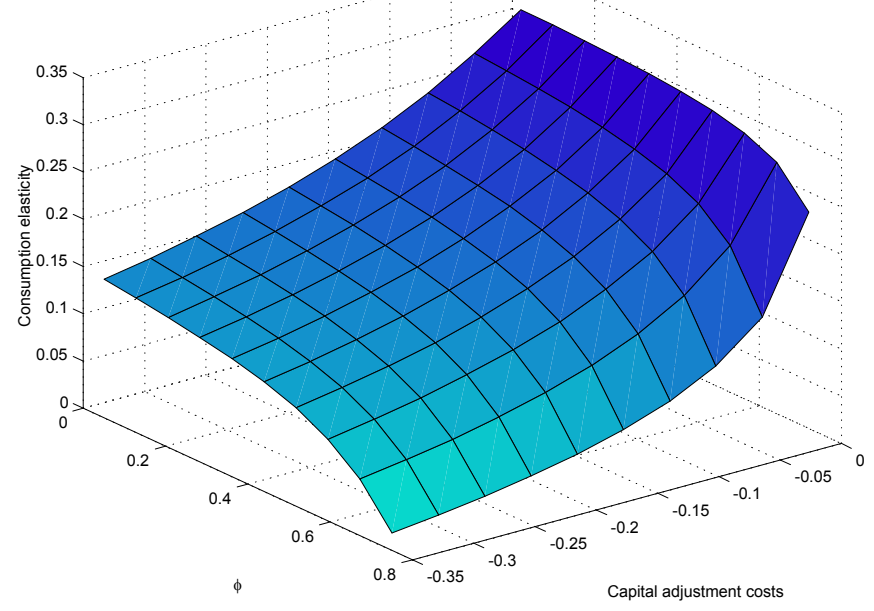

Figure 2: The elasticity of consumption volatility to government size as a function of nominal and real rigidities when public consumption is acyclical. 
Table 4

Sensitivity to parameter changes

\begin{tabular}{lrrrrrrrr}
\hline \hline & \multicolumn{3}{c}{ Output } & & \multicolumn{3}{c}{ Consumption } \\
\cline { 2 - 3 } \cline { 6 - 8 } & $\sigma_{y}$ & $\sigma_{y}$ & $\frac{\partial \ln \sigma_{y}}{\partial \ln (G / Y)}$ & & $\sigma_{c}$ & $\sigma_{c}$ & $\frac{\partial \ln \sigma_{c}}{\partial \ln (G / Y)}$ \\
& $\eta=0.5$ & $\eta=1.5$ & & & $\eta=0.5$ & $\eta=1.5$ & \\
$\sigma=2$ & 0.636 & 0.483 & -0.251 & & 0.339 & 0.327 & -0.034 \\
$\gamma=0.63$ & 0.931 & 0.746 & -0.202 & & 0.759 & 0.813 & 0.062 \\
$\alpha_{g}^{y}=-1.0$ & 0.742 & 0.510 & -0.341 & & 0.666 & 0.717 & 0.067 \\
$\sigma=2, \gamma=2.0$, & 0.546 & 0.363 & -0.372 & & 0.330 & 0.315 & -0.043 \\
$\alpha_{g}^{y}=-1.0$ & & & & & & & \\
\hline \hline
\end{tabular}

volatility, this effect gets weaker in economies where rigidities are larger. In other words, there is also an interesting interaction between government size and rigidities when it comes to the volatility of consumption and investment. Without rigidities (the RBC model) larger governments increase the volatility of consumption and investment by a larger amount than in the economy with rigidities. As a result, the stabilizing effect of higher $G / Y$, which is identical for all simulations via the composition effect, more than compensates the increase in consumption and investment volatility that results from the increase in $G / Y$ only in the case of an economy with strong rigidities.

Why does the response of investment and consumption become less dependent on government size in the presence of rigidities? The intuition is similar to what we described in previous paragraphs. More rigidities generally lead to a lower response of investment to productivity shocks. As this multiplier goes down, it also becomes less responsive to changes in government size. In summary, while larger governments make the response of investment to productivity more pronounced, this effect is smaller for economies with more rigidities. The behavior of consumption follows that of investment.

Are our results dependent on the parameter values? We have conducted some sensitivity tests by changing some of the parameter values in the utility function $(\sigma, \gamma)$ and/or in the response of public consumption (which was acyclical in our benchmark). ${ }^{5}$ Results are displayed in Table 4 . In all cases, the main results are practically unchanged.

5 In order to have a countercyclical public consumption we add the following fiscal rule to the model:

$$
\widehat{g}_{t}=\alpha_{g}^{y} \widehat{y}_{t}
$$

If $\alpha_{g}^{y}$ is negative public consumption decreases when output augments. 
The volatility of output goes down in all cases (and by a similar amount) as government size increases. When it comes to the volatility of consumption, the results are slightly different as, under some parameter values, the volatility of consumption also goes down when government size increases. But this decline is still smaller than what we observed in the data.

In summary, these preliminary results show that the model with real and nominal rigidities is partially able to account for the empirical evidence about volatility and government size. While it can account for some of the stabilizing effects on output volatility, it cannot justify the stabilizing effect that we also observe empirically on consumption. We now explore an extension of the model that can help us match this behavior.

\subsection{Introducing rule-of-thumb consumers}

We now consider that only a proportion of consumers can borrow and lend in the financial markets, whereas others are restricted in the sense that they choose consumption and leisure to maximize utility on a period-by-period basis. ${ }^{6}$ By looking at this class of consumers that cannot borrow or lend but simply spend all their current income, we hope to uncouple the dynamics of investment and wealth from that of consumption. In that sense, the response of consumption for those individuals should closer mimic that of GDP.

A proportion $(\lambda)$ of consumers will spend all of their current income as consumption while the rest will follow the same optimizing behavior as in the previous version of the model. Representing by $c_{r t}, l_{r t}$ and $c_{o t}, l_{o t}$ consumption and labour supply of restricted and optimizing consumers respectively, rule-of-thumb consumers face the following budget restriction,

$$
P_{t}\left(1+\tau_{t}^{c}\right) c_{r t}=P_{t}\left(1-\tau_{t}^{w}\right) w_{t} l_{r t}+P_{t} \lambda g_{t}^{s}
$$

Solving now the model, after the aggregation of the optimality conditions for both types of consumer, the equilibrium described by the previous equations (12) to (26) includes two new conditions

$$
\begin{gathered}
c_{t}=\frac{\lambda}{\left(1+\tau_{t}^{c}\right)}\left[\frac{\left(1-\tau_{t}^{w}\right) w_{t}}{1+\gamma}+\frac{\lambda g_{t}^{s}}{1+\gamma}\right]+(1-\lambda) c_{o t} \\
l_{t}=\frac{\lambda}{1+\gamma}\left[1-\frac{\gamma \lambda g_{t}^{s}}{\left(1-\tau_{t}^{w}\right) w_{t}}\right]+(1-\lambda) l_{o t}
\end{gathered}
$$

6 These are 'rule-of-thumb' consumers in Galí, López-Salido and Vallés (2003) terminology. 
Table 5

Government size and output with $\lambda=0.65$

\begin{tabular}{lrrrrrrrr}
\hline \hline & \multicolumn{3}{c}{ Output } & & \multicolumn{3}{c}{ Consumption } \\
\cline { 2 - 3 } \cline { 6 - 8 } & $\sigma_{y}$ & $\sigma_{y}$ & $\frac{\partial \ln \sigma_{y}}{\partial \ln (G / Y)}$ & & $\sigma_{c}$ & $\sigma_{c}$ & $\frac{\partial \ln \sigma_{c}}{\partial \ln (G / Y)}$ \\
$\Theta=\phi=0.0$ & $\eta=0.5$ & $\eta=1.5$ & & & $\eta=0.5$ & $\eta=1.5$ & \\
$\Theta=0.0, \phi=0.75$ & 1.894 & 1.921 & 0.013 & & 1.015 & 1.316 & 0.236 \\
$\Theta=0.25, \phi=0.0$ & 2.287 & 2.151 & -0.056 & & 1.461 & 1.494 & 0.020 \\
$\Theta=0.25, \phi=0.75$ & 1.578 & 1.405 & -0.106 & & 1.221 & 1.459 & 0.162 \\
& 0.853 & 0.526 & -0.440 & & 1.297 & 0.501 & -0.867 \\
\hline \hline
\end{tabular}

whereas the Euler equation (14) now changes to

$$
1=\beta E_{t}\left(\frac{\left(1+\tau_{t}^{c}\right) c_{o t+1}^{-\sigma}\left(1-l_{o t+1}\right)^{\gamma(1-\sigma)}}{\left(1+\tau_{t+1}^{c}\right) c_{o t}^{-\sigma}\left(1-l_{o t}\right)^{\gamma(1-\sigma)}} \frac{1+i_{t+1}}{\pi_{t+1}}\right)
$$

Results for the calibrations of the model with rule-of-thumb consumers are shown in Table 5, which is identical in structure to Table 3. Moving down across rows we see how, in an economy with a substantial proportion of rule-of-thumb consumers, the stabilizing effect of large governments shows up more clearly. Unlike in the model in the previous section, now as government size increases, consumption becomes less volatile. As a result, the stabilizing effect on output that we had documented already in Table 3 becomes much stronger. For example, in the last row we see that the elasticity of output volatility with respect to government size is now -0.44 , which is substantially larger than what we found in Table 3 and close to the empirical estimates of Table 1.

Figure 3 illustrates the role of rule-of-thumb consumers in the calibrations. The share of this class of consumers does not have a large effect on the volatility of output and its elasticity except above certain level of price rigidities and capital adjustment costs. In other words, the presence of rule-of-thumb consumers only makes a difference in economies with strong nominal and real rigidities. In fact, when $\phi$ and $\Theta$ are close to zero, as in a RBC model, the value of $\lambda$ does not affect the standard deviation of private consumption. Therefore, it is the interaction between those rigidities and the share of restricted consumers that decreases consumption volatility.

Understanding the intuition behind this result is crucial to have a complete picture of the mechanisms that explain why larger governments are associated to reduced consumption volatility. Because constrained consumers will spend all their current in- 

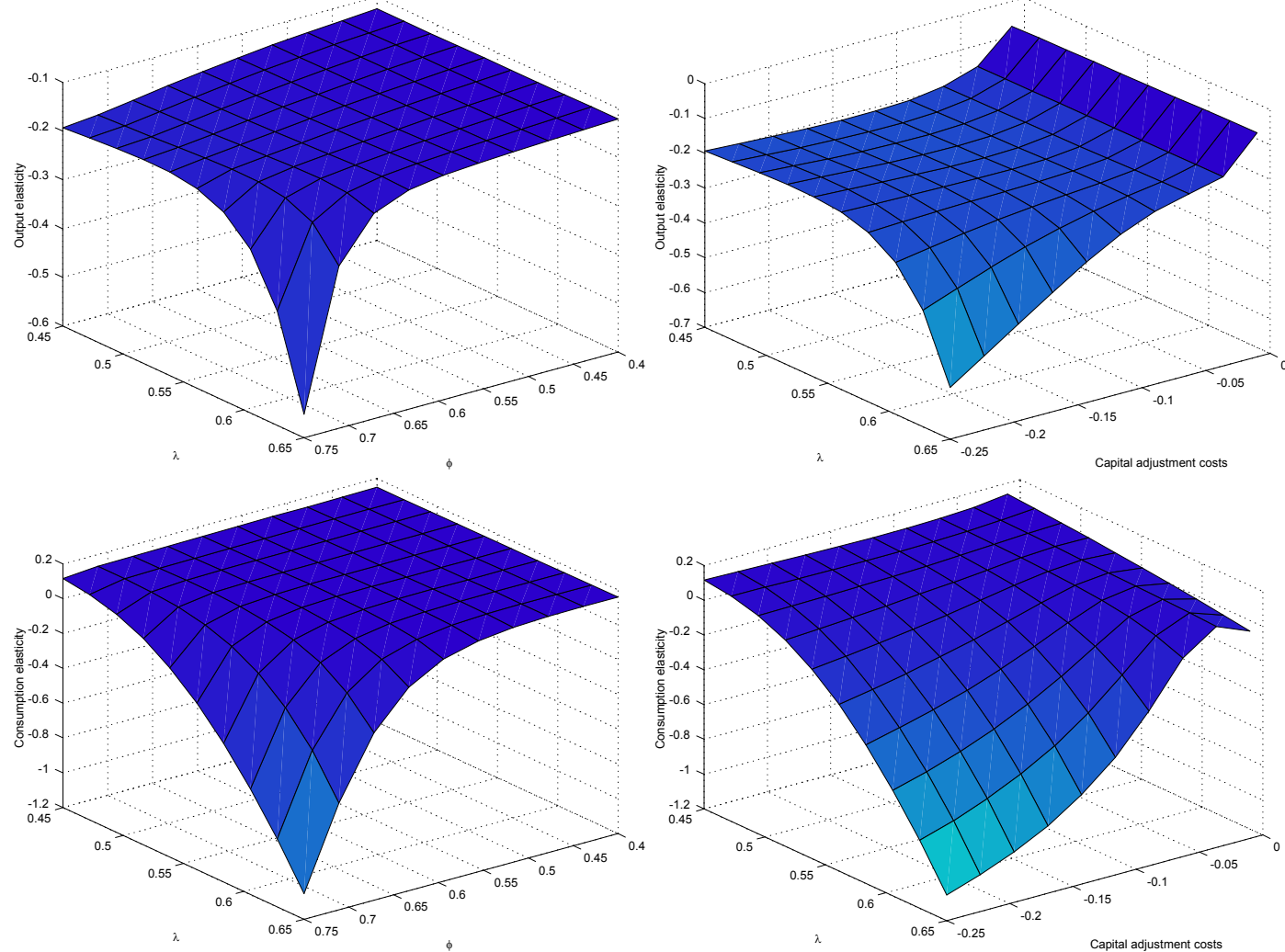

Figure 3. Output and consumption elasticity as a function of $\lambda$, nominal rigidities and capital adjustment costs.

come, we need to understand how hours and wages change in response to productivity shocks and how this response is affected by the size of government and rigidities.

The empirical response of hours and wages to productivity shocks is a much debated issue in the literature. Some of the recent empirical work in this area has established the result that hours tend to fall on impact following a positive technology shock (see, for example, Rotember (2003) or Galí (1999)). While this result is at odds with a standard RBC model, it can easily be accomodated within a model with significant nominal rigidities as discussed by Gali (1999). The intuition is simple. With the money supply being fixed (or not too accommodative), and prices not being able to change, firms face constant demand (or unchanged output) and this means, for a higher level of productivity, that employment has to go down. In economies with substantial rigidities, 
real wages fall on impact for very much the same reasons as employment does in the presence of technology shocks. The response of real wages is the standard one as labour demand temporarily falls along an upward sloping labour supply curve. Despite this short-run fall on labour income consumption should not fall if consumers are forward looking since permanent income rises as a result of the technology shock. This is what we observe in our calibrations as well. In the absence of rigidities, hours and real wages increase after a productivity shock. With a high-enough degree of nominal rigidities the response of wages and hours becomes the opposite as in Gali (1999). But, still, consumption increases as long as consumers are forward looking and they are able to spend the future expected increases in income.

When a significant proportion of consumers are constrained the behavior of consumption changes. In fact, rule-of-thumb consumers are forced to reduce their consumption along with their current labour income in the first quarters after the shock. This explains the behavior of consumption given a government size, but how does this behavior change when we increase government size? Larger governments, in our simulations, help to smooth the income of consumers in the periods that follow the productivity shock. By moderating the fall in labor income of the rule-of-thumb consumers, it also moderates the fall in their consumption and, as a result, consumption becomes less volatile. As the size of government increases, the marginal rate of labour taxes augments making labour supply more elastic, which implies a lower response of wages. This lower response of wages also explains the lower change of consumption for the constrained consumers. In summary, government size stabilizes consumption by stabilizing employment, wages and income for those consumers who are constrained, as a result, large governments make total consumption and output less volatile.

\section{Conclusions}

How effective are automatic stabilizers? Does fiscal policy smooth economic fluctuations? These are open questions at the forefront of public and policy debates on the role of fiscal policy. Empirical evidence suggests that large governments have a stabilizing effect on consumption and output, that is, countries with large governments display less volatile business cycles. Our analysis starts by taking this stylzed fact as given and analyzes from a theoretical point of view which type of models can explain the observed negative correlation between government size and volatility. Understanding the exact mechanisms through which fiscal policy interacts with the business cycle is necessary to extract policy implications out of that empirical fact. At the same time, we also provide a test of alternative models of the business cycle by testing them against a very specific and well defined prediction: that large governments stabilize output. 
In our analysis we find that a variety of frictions are necessary to replicate the empirical evidence. A standard RBC model with technology shocks cannot produce the negative correlation that exists between government size and output volatility in the data.

We find that the volatility of output falls with the rise of government size provided that the economy features enough nominal and real rigidities. As prices changes are less frequent and capital adjustment costs are larger, we find that the elasticity of output volatility to government size becomes more negative and significant as compared with the RBC model, in which this elasticity is practically zero. In our initial baseline model, this reduced volatility is mostly coming via a composition effect. As government size increase, it is still the case that both consumption and investment become more volatile but because the non-volatile component of output is becoming larger, total volatility decreases.

While this result is encouraging, it does not explain sufficiently empirical facts because, in the data, we also observe less volatile consumption when government size increases. To address this deficiency of the model, we introduce rule-of-thumb consumers. We find that in this case both the volatility of output and consumption falls with the rise of the government size provided that these rigidities and the proportion of rule-of-thumb consumers are both sufficiently large. We show that both these features are needed in a dynamic general equilibrium model to mimic the correlations observed in the data.

Our results show that models with Keynesian features can better replicate the empirical evidence on the effects of fiscal policy on the volatility of output fluctuations. The spirit of our analysis is similar to recent attempts to explain other stylized facts of fiscal policy (such as the positive response of consumption to increases in government spending) that also require models that combine nominal and real rigidities with ruleof-thumb consumers.

\section{References}

Agresti, A. M. and B. Mojon (2001): "Some Stylised Facts on the Euro Area Business Cycle". ECB Working Paper No. 95.

Alesina, A., O. Blanchard, J.Galí, F. Giavazzi and H. Uhlig (2001): Defining a Macroeconomic Framework for the Euro Area. Monitoring the European Central Bank 3. CEPR.

Alesina, A. and R. Perotti (1997): "Fiscal Adjustments in OECD Countries: Composition and Macroeconomic Effects". IMF Staff Papers, 44(2), 210-248.

Andrés, J. and R. Domenech (2003): "Automatic Stabilizers, Fiscal Rules and Macroeconomic Stability". Working Paper No. 0314. Banco de España. 
Ballabriga, F. and C. Martinez-Mongay (2002): "Has EMU Shifted Policy?". Mimeo. European Commission.

Baxter, M. and R. G. King (1993): "Fiscal Policy in General Equilibrium". American Economic Review, 83, 315-334.

Baxter, M. y R. G. King (1999): "Measuring Business Cycles: Approximate Band-Pass Filters for Economic Times Series". The Review of Economics and Statistics, 81(4), 575--593.

Bernanke, B. S., M. Gertler and S. Gilchrist (1999): "The Financial Accelerator in a Quantitative Business Cycle Framework", in J. B. Taylor and M. Woodford, eds., Handbook of Macroeconomics, vol. 3. Elsevier.

Blanchard, Olivier and Roberto Perotti (2002): "An Empirical Characterization of the Dynamic Effects of Changes in Government Spending and Taxes on Output". Quarterly Journal of Economics, November, 1329-48.

Bohn, H. (1998): "The Behavior of Public Debt and Deficits". The Quarterly Journal of Economics, 113, 949-963.

Buti, Marco and Paul van den Noord (2003): "Fiscal Policy in EMU: Rules, Discretion and Political Incentives" Mimeo.

Calvo, G. (1983): "Staggered Prices in a Utility Maximizing Framework". Journal of Monetary Economics, 12(3), 383-98.

Canzoneri, M. B., R . E. Cumby and B. Diba (2001): "Is the Price Level Determined by the Needs of Fiscal Solvency?". American Economic Review, 91(5), 1221-38.

Christiano, J. L. and M. Eichenbaum (1992): "Current Real-Business-Cycle Theories and Aggregate Labor Market Fluctuations". American Economic Review, 82(3), 430-50.

Christiano, J. L., M. Eichenbaum and C. Evans (1997): "Sticky Price and Limited Participation Models of Money: A Comparison". European Economic Review, 41, 1201-49.

Clarida, R., J.Galí and M. Gertler (1999): "The Science of Monetary Policy: A New-Keynesian Perspective". Journal of Economic Literature, 37, 1661-1707.

Cogley, T. and J. M. Nason (1995): "Effects of the Hodrick-Prescott Filter on Trend and Difference Stationary Time Series. Implications for Business Cycle Research". Journal of Economic Dynamics and Control, 19, 253-278.

Cooley, T. F. and E. C. Prescott (1995): "Economic Growth and Business Cycles", in T. F. Cooley (ed.): Frontiers of Business Cycle Research. Princeton University Press.

Corsetti and Roubini (1996): "European versus American Perspectives on Balanced-Budget Rules". American Economic Review, 86(2), 408-13.

Doménech, R., Ledo, M. and D. Taguas (2002): "Some New Results on Interest Rates Rules in EMU and in the US". Journal of Economics and Business, 54(4), 431-46

Fatás, A. and I. Mihov (2001): "Government Size and Automatic Stabilizers: International and Intranational Evidence". Journal of International Economics, 55(1), 3-28.

Fatás, Antonio and Ilian Mihov (2002): "The Effects of Fiscal Policy on Consumption and Employment: Theory and Evidence". Mimeo. INSEAD.

Galí, J. (1994): "Government Size and Macroeconomic Stability". European Economic Review, 38(1), 117-132. 
Galí, J. (1999): "Technology, Employment, and the Business Cycle: Do Technology Shocks Explain Aggregate Fluctuations". American Economic Review, 89(1), 249-71.

Galí, J., M. Gertler and D. López-Salido (2001): "European Inflation Dynamics". European Economic Review, 45, 1237-70.

Galí, J., D. López-Salido and J. Vallés (2003): "Understanding the Effects of Government Spending on Consumption". Mimeo. CREI.

King, R. G., C. I. Plosser and S. Rebelo (1988): "Production, Growth and Business Cycles: II. New Directions". Journal of Monetary Economics, 21, 309-341.

Leeper, E. (1991): "Equilibria under 'Active' and 'Passive' Monetary and Fiscal Policies". Journal of Monetary Economics, 27, 129-147.

Leith, C. and S. Wren-Lewis (2000), "Interactions between monetary and fiscal policy rules", The Economic Journal, 110, 93-108.

Linnemann, L. and A. Schabert (2000): "Fiscal Policy in the New Classical Synthesis". Mimeo. University of Cologne.

Maravall, A. y A. del Río (2001): "Time Aggregation and The Hodrick-Prescott Filter". Working Paper No. 0108. Banco de España.

Martínez-Mongay, C. (2002): "Fiscal Policy and the Size of Governments", in M. Buti, J. von Hagen, and C. Martinez-Mongay (eds.): The Behavior of Fiscal Authorities. Stabilization, Growth and Institutions, Chapter 5. Basingstoke: Palgrave.

Martínez-Mongay, C. and K. Sekkat (2003): "The Trade-off between Efficiency and Macroeconomic Stabilization in Europe". Mimeo. European Commission.

Mendoza, E., A. Razin and L. Tesar (1994): "Effective Tax Rates in Macroeconomic Cross-Country Estimates of Tax Rates on Factor Incomes and Consumption". Journal of Monetary Economics 34(3), 297-324.

Perotti, R. (2002): "Estimating the Effects of Fiscal Policy in OECD Countries". Working Paper No. 168. European Central Bank.

Rotemberg, J. J. (2003): "Stochastic Technical Progress, Smooth Trends, and Nearly Distinct Business Cycles". American Economic Reviewpp. 1543-1559.

Sbordone, A. (2002): "Prices and Unit Labor Costs: A New Test of Price Stickiness". Journal of Monetary Economics, 49, 265-292.

Silgoner, M.A., G. Reitschuler and Crespo-Cuaresma (2003): "Assessing the Smoothing Impact of Automatic Stabilizers: Evidence from Europe", in Tumpel-Gugerell and Mooslechner (eds.), Structural Challenges for Europe, Edward Elgar.

van den Noord, P. (2000): "The Size and Role of Automatic Fiscal Stabilizers in the1990s and Beyond". OECD Economics Department Working Papers, No. 230.

von Hagen, J., A.C. Hallet and R. Strauch (2001): "Budgetary Consolidation in EMU". Economic Papers, No. 148. European Communities.

Woodford, M. (1996): "Control of the Public Debt: A Requirement for Price Stability?". NBER Working Paper no. 5684. 